\title{
Propiedades biomecánicas y proceso de esterilización de las matrices alodérmicas usadas en periodoncia ${ }^{1}$
} Biomechanical properties and sterilization process of allodermics matrix
used on periodontics

\author{
ARDILA MEDINA CM*
}

Ardila Medina CM. Propiedades biomecánicas y proceso de esterilización de las matrices alodérmicas usadas en periodoncia. Av Periodon Implantol. 201 1; 23, 3: 187-193.

\begin{abstract}
RESUMEN
Se han propuesto diferentes procedimientos quirúrgicos para la preservación y aumento del reborde alveolar, así como para el tratamiento de recesiones gingivales e incremento de la amplitud de la encía adherida, alrededor de dientes naturales e implantes. Cuando se utilizan injertos autógenos en estas intervenciones se evidencian algunas desventajas que incluyen la inconformidad asociada con un sitio quirúrgico adicional y la disponibilidad limitada de tejido donante. Recientemente, se utilizan como sustitutos de los injertos autógenos en cirugía periodontal, dos tipos de aloinjertos de matriz dérmica acelular. Debido al gran uso de matrices alodérmicas, no solo en periodoncia sino en otras áreas de las ciencias de la salud, se ha dispuesto mayor atención a las medidas de seguridad y a la eficacia de varios procesos de esterilización realizados por los bancos tisulares. Desafortunadamente, el procesamiento y las técnicas de esterilización podrían producir efectos deletéreos sobre las propiedades biomecánicas de los tejidos alogénicos, ocasionando resultados indeseables en las intervenciones realizadas. Por otra parte, se ha indicado que a pesar de la rigurosidad de los procesos de evaluación en donantes y tejidos, además del procesamiento extenso de las matrices, existe la posibilidad de permanencia de material genético en los aloinjertos disponibles comercialmente.
\end{abstract}

PALABRAS CLAVE: Aloinjertos, esterilización, propiedades mecánicas.

\section{SUMMARY}

Several surgical procedures have been proposed for the preservation and increase of the alveolar ridge, and for the treatment of gingival recessions and to increase the width of attached gingiva around natural teeth or implants. The disadvantages of harvesting autogenous grafts on these procedures lie in the postoperative discomfort associated with an extra surgical site, as well as the limitation of available donor tissue. Recently, two types of acellular dermal matrix allografts have been approved as substitutes for autogenous grafts in mucogingival surgery. Due to the increased use of allografts on periodontics and other areas of health sciences, has brought more focus to the safety of allogenic tissue and the efficacy of various sterilization techniques. Unfortunately, these sterilization techniques could produce deleterious effects on the biomechanical properties of allogenic tissues, causing undesirable results on the interventions. Moreover, it has been suggested that despite the thoroughness of the evaluation processes and tissue donors, in addition to the processing of the matrices, there is possibility of retention of genetic material on allografts commercially available.

KEY WORDS: Allografts, sterilization, mechanical properties.

Fecha de recepción: 2 de junio de 2008.

Aceptado para publicación: 16 de junio de 2008.

Trabajo presentado en el $3^{\text {er }}$ Congreso Internacional de Implantología Oral. Bogotá. Colombia, Mayo de 2009.

Profesor Asistente. Facultad de Odontología. Universidad de Antioquía. Miembro de la Junta Directiva de la Asociación Colombiana de Periodoncia y Oseointegración. 


\section{INTRODUCCIÓN}

Se han indicado diferentes procedimientos quirúrgicos para la preservación y aumento del reborde alveolar, así como para el tratamiento de recesiones gingivales e incremento de la amplitud de la encía adherida, alrededor de dientes naturales e implantes. Las terapias recomendadas comprenden injertos autógenos de tejidos blandos combinados o no con colgajos (1), materiales aloplásticos no reabsorbibles (2), y regeneración tisular/ósea guiada (3). Recientemente, una matriz dérmica acelular (MDA) se ha utilizado ampliamente en cirugía periodontal para corregir defectos mucogingivales y alveolares (4-6). La MDA es un aloinjerto libre de células obtenido de la piel humana, bioestructuralmente compuesto por membrana basal y matriz extracelular. Además de eliminar la inconformidad relacionada con un sitio quirúrgico adicional y la disponibilidad limitada de tejido donante, actúa como una matriz que permite la neovascularización, y proliferación de fibroblastos y células epiteliales (5). La infección post operatoria después del uso de un aloinjerto humano puede traer consecuencias desafortunadas. Los factores de riesgo asociados con infección comprenden edad del paciente, hábito de fumar, duración de la cirugía y procedimientos operatorios previos (7). Un factor de riesgo específico para infecciones asociadas a aloinjertos es la posibilidad de transmisión iatrogénica de enfermedades (8). Esto puede ocasionar complicaciones locales y sistémicas, incluyendo la muerte. Los aloinjertos procesados y obtenidos asépticamente, no son necesariamente estériles, permitiendo transmisiones virales y bacterianas (8). Con el fin de mejorar la seguridad de los aloinjertos, los bancos tisulares han enfocado su atención no solo en el mejoramiento de los procesos de esterilización, sino también en la exploración de los donantes y en la aplicación de pruebas de verificación. Las MDAs usadas en periodoncia son Alloderm ${ }^{\circledR}$ y Puros ${ }^{\circledR}$ Dermis, presentando diferencias en sus características generales, propiedades biomecánicas y mecanismo de procesamiento (Tablas 1 y 2 ). La primera es liofilizada y la segunda es preparada por un procesamiento patentado (Tutoplast ${ }^{\circledR}$ ). El objetivo de este artículo es presentar la eficacia de las técnicas de preparación y esterilización aplicadas en las matrices dérmicas usadas en periodoncia, y las implicaciones sobre sus propiedades biomecánicas.

\section{PREPARACIÓN DE LA MATRIZ EXTRACELULAR Y PROPIEDADES BIOESTRUCTURALES}

La matriz extracelular (MEC) es diseñada y producida por las células residentes de cada tejido y órgano, encontrándose en un estado de equilibrio dinámico con su entorno (9). La estructura y función molecular de la MEC proporciona los medios por los cuales las células adyacentes se comunican entre ellas y con el ambiente externo (10). Además, proporciona un medio de soporte para nervios, vasos sanguíneos y linfáticos,

\section{TABLA 1.- CARACTERÍSTICAS GENERALES Y PROPIEDADES BIOIMECÁNICAS DE LAS MATRICES ALODÉRIMICAS USADAS EN PERIODONCIA}

\begin{tabular}{|l|l|l|}
\hline & Alloderm & \\
\hline Resistencia & $4,5 \mathrm{lbs} \pm 1,1$ & Puros $^{\circledR}$ Dermis Allograft \\
\hline Rehidratación & Dos enjuagues de 5 minutos c/u & $5,0 \mathrm{lbs} \pm 0,8$ \\
\hline Almacenamiento & Refrigerado & $0-30$ minutos \\
\hline Vida útil & 2 años & Temperatura ambiente \\
\hline Espesor & $0,9 \mathrm{~mm}-1,6 \mathrm{~mm}$ & 5 años \\
\hline Diámetros & $1 \mathrm{~cm} \times 1 \mathrm{~cm}$ & $0,8 \mathrm{~mm}-1,8 \mathrm{~mm}$ \\
& $1 \mathrm{~cm} \times 2 \mathrm{~cm}$ & $1 \mathrm{~cm} \times 1 \mathrm{~cm}$ \\
& $1 \mathrm{~cm} \times 4 \mathrm{~cm}$ & $1 \mathrm{~cm} \times 2 \mathrm{~cm}$ \\
& $2 \mathrm{~cm} \times 4 \mathrm{~cm}$ & $2 \mathrm{~cm} \times 4 \mathrm{~cm}$ \\
\hline Residuos & Antibióticos & Ninguno \\
\hline
\end{tabular}




\section{TABLA 2.- PROCESO DE PREPARACIÓN DE LAS MATRICES ALODÉRIMICAS USADAS EN PERIODONCIA}

\begin{tabular}{|l|l|}
\hline Alloderm $^{\circledR}$ & Puros $^{\circledR}$ Dermis Allograft-Tutoplast \\
& ${ }^{\circledR}$ \\
\hline Selección del donante. & Selección del donante. \\
\hline Evaluación serológica del donante. & Evaluación serológica del donante. \\
\hline Remoción de la epidermis. & Remoción de la epidermis. \\
\hline $\begin{array}{l}\text { Lavado tisular con solución salina balanceada de } \\
\text { Hanks. }\end{array}$ & Tratamiento osmótico (solución salina hiperosmótica). \\
\hline $\begin{array}{l}\text { Descelularización (dodecilsulfato sódico al 0,5\% } \\
\text { en solución salina balanceada). }\end{array}$ & Descelularización (peróxido de hidrógeno). \\
\hline Deshidratación-antibióticos-liofilización. & Deshidratación (acetona). \\
\hline Evaluación mecánica. & Evaluación mecánica. \\
\hline Empaque. & Empaque. \\
\hline & Irradiación gama (17,8 KGy-25 KGy). \\
\hline & Hidróxido de sodio. \\
\hline
\end{tabular}

y para la difusión de nutrientes (9). No se ha caracterizado completamente la compleja organización tridimensional de la estructura y función molecular que compone la MEC, haciendo imposible la síntesis de este biomaterial en el laboratorio (11). Se han usado varias formas de MEC como matrices biológicas para promover la remodelación de tejidos y órganos, incluyendo piel, intestino, hígado y páncreas, entre otros tejidos (9). Muchas de estas MEC se han comercializado para aplicaciones terapéuticas variadas.

Las características microscópicas y estructurales de la matriz juegan un papel importante en la modulación de las células que la contactan, controlando su habilidad para migrar en la MEC o influyendo sobre un fenotipo celular específico (11). La estructura y arquitectura tridimensional de la MEC se puede preservar a través de procesos que requieren la eliminación de las células (11). La preparación de la MEC, a partir de un tejido, se realiza durante varias etapas que pueden afectar sustancialmente la bioestructura del aloinjerto y el tipo de respuesta inflamatoria e inmunológica del huésped (9). El tejido donante a partir del cual se prepara la MEC debe ser separado mecánicamente de estructuras tisulares indeseables. Diferentes bancos tisulares han empleado procesos y protocolos distintos para asegurar una desinfección y esterilización apropiada de los aloinjertos. No existe un proceso de esterilización mandatorio que sea exigido por la administración de alimentos y drogas de los Estados Unidos (FDA). Cada banco tisular utiliza una combinación compleja de técnicas patentadas incluyendo irradiación, remojo y lavado con antibióticos, liofilización y criopreservación, entre otras. Después de llevar a cabo estos protocolos, se efectúa con frecuencia una esterilización terminal mediante irradiación gamma o con óxido de etileno.

También existe gran variedad de formas para obtener la MEC de los tejidos y eliminar el contenido celular (9). La remoción de componentes antigénicos asociados con las membranas celulares y componentes intracelulares de órganos y tejidos es fundamental para disminuir o evitar una respuesta inmunológica adversa (9).

El principal objetivo de cualquier protocolo de descelularización es remover todo el material celular sin afectar la composición, integridad mecánica y actividad biológica de la MEC remanente (9). Después de eliminar el contenido celular mediante alguno de los métodos utilizados (sonificación, agitación, congelación y descongelación), se realiza un enjuague y remoción de las células remanentes en la MEC (11). Algunos detergentes usados en este proceso pueden dañar el colágeno, alterando las propiedades mecánicas de la MEC (12). Lovekamp y cols. (13), demostraron 
que la remoción de las glucosaminas del aloinjerto puede tener un efecto negativo sobre el comportamiento viscoelástico del tejido, debido a que una de sus mayores características funcionales es la retención de agua.

A raíz del proceso de eliminación de células y esterilización, muy pocos aloinjertos mantienen un estado de hidratación (9). Se pueden prevenir cambios en la estructura tisular, tales como el colapso de las fibras colágenas y la formación de adherencias físicas entre las moléculas de la matriz, impidiendo la pérdida de agua (11). Microscopía electrónica de matrices hidratadas y liofilizadas demuestran cambios en la arquitectura tisular después de la remoción del agua (9). Los aloinjertos que conservan su hidratación después del proceso de eliminación de células y esterilización tienden a presentar in vitro mejor adhesión e infiltración celular que las matrices sometidas a deshidratación y rehidratación (14). Sin embargo, la mayor desventaja de los materiales hidratados, es la filtración continua de factores de crecimiento solubles desde el aloinjerto durante su proceso de almacenamiento (9).

Los aloinjertos son deshidratados con frecuencia mediante liofilización antes de la esterilización final. La deshidratación favorece la manipulación de los injertos y limita la pérdida de factores de crecimiento durante el almacenamiento (11). Algunos investigadores han documentado cambios bioestructurales de aloinjertos procesados mediante liofilización. Es así como Freytes y cols. (14), observaron que la liofilización disminuye in vitro la máxima elongación de las matrices, alterando la morfología de las fibras colágenas y el crecimiento de las células sobre el injerto. Adicionalmente, matrices liofilizadas almacenadas a temperatura ambiente o refrigeradas por períodos superiores a un año, mostraron un incremento en la carga y rigidez máxima, y un aumento en la elongación máxima, respectivamente (15). Por otra parte, Gilbert y cols. (16), encontraron que la liofilización disminuye significativamente el espesor de la matriz pero también reduce la habilidad del material para reabsorber la misma cantidad de agua que estuvo presente antes de someterse al proceso de liofilización, debido a la remoción de glucosaminas. Algunos bancos tisulares combinan antibióticos y liofilización, sin embargo, la contaminación bacteriana puede ser reducida pero no completamente eliminada mediante lavado con soluciones antibióticas (17). Además, antes de realizar la intervención, es necesario evaluar si el paciente es alérgico a los antibióticos usados.

Diferentes estudios han indicado que la esterilización final de los aloinjertos también puede tener un efecto perjudicial sobre sus propiedades bioestructurales $(9$, 18-20). Recientemente, se demostró una disminución de las propiedades mecánicas de la MEC después de la exposición a óxido de etileno, irradiación electrónica e irradiación gamma (18). Gouk y cols. (19), estudiaron los efectos de la irradiación gamma sobre el Alloderm ${ }^{\circledR}$, encontrando que dosis menores a $15 \mathrm{kGy}$ (dosis gamma baja) incrementa la solidez de las matrices dérmicas y no afecta la proliferación de fibroblastos in vitro, sin embargo, sus propiedades se minimizan en dosis gamma superiores, ocasionando reducción significativa de la elasticidad del aloinjerto y mayor susceptibilidad a la degradación proteolítica, influyendo en la síntesis y depósito de nuevo colágeno (19). Estos resultados fueron corroborados por Balsly y cols. (20), utilizando aloinjertos de tejidos blandos y duros, pero empleando un punto de corte superior para la irradiación gamma baja (18,3-21,8 kGy). No se ha estudiado detalladamente el mecanismo que ocasiona cambios en las propiedades bioestructurales después de usar oxido de etileno e irradiación electrónica (9), pero se han documentado reacciones tisulares del huésped cuando se usan aloinjertos tratados con oxido de etileno (21).

\section{PRESENCIA DE MATERIAL GENÉTICO EN LOS ALOINJERTOS}

Los donantes de aloinjertos son examinados para evaluar la presencia de algunas patologías y los tejidos donados son especialmente procesados para prevenir la transmisión de enfermedades. Los donantes son serológicamente evaluados para enfermedades virales tales como VIH, hepatitis B y C, citomegalovirus, virus linfotrófico-T humano y sífilis. Posteriormente se determina la carga bacteriana en el injerto y se descarta cualquier tejido que presente niveles altos de contaminantes o niveles microbianos elevados. Sin embargo, es posible encontrar patógenos e infecciones en los aloinjertos a pesar de someterse a procesos de evaluación rigurosos, debido principalmente a las limitaciones de la metodología de evaluación (22). La liofilización es un proceso que disminuye la inmunogenicidad de los tejidos removiendo el agua inter e intra molecular, mediante sublimación a temperaturas y presiones bajas (9), sin embargo, se ha informado la inhabilidad de este proceso para inactivar completamente el VIH $(23,24)$. En el año 2004 un estudio evaluó las tasas de virulencia en los tejidos donados en Estados Unidos (25). La prevalencia de pruebas positivas confirmadas en los aloinjertos fue: $0,093 \%$ para antiVIH, 0,22\% para antígeno de hepatitis B, 1,091\% para 
antivirus hepatitis $\mathrm{C}$, y $0,068 \%$ para antivirus linfotrófico-T. Los autores concluyeron que las tasas de prevalencia de infecciones por los virus mencionados anteriormente, son inferiores en los donantes de tejidos, comparados con la población general. Sin embargo, la probabilidad de virulencia no detectada en el momento de la donación de tejido es más alta en los donantes de tejidos que en los donantes de sangre. Además, un patógeno puede ser transmitido durante el período de ventana inmunológica, etapa en el cual es serológicamente indetectable (26), posibilidad que es remota si se aplica un examen de ácidos nucleicos $(27,28)$. Sin embargo, el examen de ácidos nucleicos disminuye esta fase a aproximadamente siete días para VIH e infecciones con virus de hepatitis $\mathrm{C}$ y a ocho días para infección con virus de hepatitis B (28). Además, solamente desde agosto de 2007, se requiere el examen de ácidos nucleicos como parte de las regulaciones de la administración de drogas y alimentos de los Estados Unidos (FDA), aunque es aplicado desde el 2005 por la Asociación Americana de Bancos Tisulares (AATB) (28).

Desafortunadamente, los donantes no son examinados para la presencia de otros $A D N$ virales (papilomavirus y virus herpes) con inmenso potencial para transmitir un espectro amplio de enfermedades (27). Igualmente, algunas patologías de aparición reciente transmitidas por priones, no pueden ser evaluadas adecuadamente por la carencia de pruebas serológicas apropiadas (29).

Los protocolos de procesamiento tisular humano varían ampliamente pero la mayoría incluye una solución de inactivación viral (27). Sin embargo, el ADN viral que se incorpora en el genoma del huésped puede ser transmitido si el ADN permanece intacto y funcional en el aloinjerto (27). Choe y Bell (30), determinaron la presencia de material genético en aloinjertos procesados comercialmente (Alloderm ${ }^{\circledR}$ y Faslata ${ }^{\circledR}$ ). Se evaluaron 16 muestras de dos tipos de aloinjertos cadavéricos humanos (dérmicos acelulares y fascia lata) liofilizados y gama irradiados. Todas las muestras fueron sometidas a extracción del ADN y se utilizó reacción en cadena de la polimerasa (PCR) para amplificarlo. Además, se efectuó espectrofotometría para cuantificar y electroforesis para determinar el tamaño de los fragmentos de ADN. El promedio de concentración de ADN en los injertos de fascia lata y dérmicos fue $258,3 \pm 80,1$ y $272,8 \pm 168,8 \mu \mathrm{g} / \mathrm{gm}$ por tejido, respectivamente. Igualmente, Hathaway y Choe (27), determinaron la presencia, cuantificaron la concentración y evaluaron la longitud del $\mathrm{ADN}$, en aloinjertos cadavéricos humanos disponibles comercialmente, me- diante el mismo protocolo empleado en el estudio descrito anteriormente. Se evaluaron 10 muestras de cada una de las siguientes marcas comerciales: Mentor Corp., Musculoskeletal Transplant Foundation, Regeneration Technologies y Life Cell Corp. Los injertos cadavéricos se procesaron después de obtener los tejidos de los donantes. El aloinjerto Tutoplast ${ }^{\circledR}$ procesado por Mentor es descelularizado, gama irradiado y tratado con peróxido de hidrógeno, hidróxido de sodio y acetona. Musculoskeletal Transplant Foundation procesa sus injertos remojándolos en gentamicina y agua estéril, y mediante liofilización. Regeneration Technologies los introduce en povidona-yodo, tratados con ácido ascórbico y procesados por liofilización. La dermis cadavérica Alloderm ${ }^{\circledR}$ de Life Cell Corp. es descelularizada, inactivada para virus y liofilizada. De las 40 muestras evaluadas 39 contenían segmentos de $A D N$ entre 400 y 2000 pares de bases (pb). Varió ampliamente la cantidad individual, sugiriendo heterogeneidad en la obtención o procesamiento de los tejidos en las diferentes marcas comerciales. Basado en la espectrofotometría, no se observaron diferencias significativas en la cantidad de $\mathrm{ADN}$ encontrado por mg. de tejido (767,5 $\mu \mathrm{g} / \mathrm{mg}$ para Mentor, $863,5 \mu \mathrm{g} / \mathrm{mg}$ para Musculoskeletal Transplant Foundation, $931 \mu \mathrm{g} /$ $\mathrm{mg}$ para Regeneration Technologies y $526 \mu \mathrm{g} / \mathrm{mg}$ para Life Cell; $p=0,07$ ). La cantidad de aloinjertos con segmentos de ADN de 400 pb, varío según la compañía procesadora ( 9 en Mentor y 10 en cada una de las marcas restantes). Se encontraron segmentos de ADN de $700 \mathrm{pb}$ en cada uno de los 10 aloinjertos tratados por tres fabricantes, mientras que en los procesados por Mentor no se halló ninguno. Se observaron segmentos de ADN de $2.000 \mathrm{pb}$, solamente en las matrices alodérmicas procesadas por Life Cell. Los autores teorizaron que el hidróxido de sodio usado por Mentor puede ser responsable de esta variabilidad, debido a su capacidad para destruir efectivamente el ADN. Señalaron además, la poca claridad del mecanismo de acción de las soluciones antimicrobianas empleadas para tratar de destruir el ADN de los aloinjertos y la poca efectividad de la liofilización para eliminar el ADN. Los autores enfatizan la limitación de la PCR para detectar segmentos de ADN superiores a $2.000 \mathrm{pb}$ y su implicación en la evaluación de los aloinjertos, ya que la longitud de muchos genomas virales, como el papiloma humano y el polioma, es de 5.000 y 8.000 pb. Los autores concluyeron que su investigación no muestra que el ADN aislado de los aloinjertos sea infeccioso, sino que está presente a pesar de procesos tisulares extensos, además, no se determinó si los segmentos genéticos encontrados provenían de los donantes o de otras fuentes como bacterias o virus. 


\section{CONCLUSIONES}

Los bancos tisulares utilizan diferentes técnicas patentadas para preparar los aloinjertos, cada una con procesos particulares. El objetivo de estas técnicas es erradicar e inactivar los microorganismos infecciosos mientras al mismo tiempo se preservan las propiedades biomecánicas de los tejidos. No existen estudios que prueben con suficiente evidencia superioridad en la efectividad o eficacia de alguno de estos procesos, lo cual implica la realización de más estudios clínicos para validarlos.

Es fundamental que el periodoncista esté familiarizado con el proceso de esterilización empleado en las matrices alodérmicas que usa en cirugía periodontal y utilizar preferiblemente aloinjertos acreditados por la Asociación Americana de Bancos Tisulares.

\section{BIBLIOGRAFÍA}

1. Fagan MC, Owens H, Smaha J, Kao RT. Simultaneous hard and soft tissue augmentation for implants in the esthetic zone: report of 37 consecutive cases. J Periodontol 2008;79:1782-8.

2. Geurs NC, Korostoff JM, Vassilopoulos PJ, Kang TH, Jeffcoat M, Kellar R, et al. Clinical and histologic assessment of lateral alveolar ridge augmentation sing a synthetic long-term bioabsorbable membrane and an allograft. J Periodontol 2008;79:1133-40.

3. Buser D, Halbritter S, Hart C, Bornstein MM, Grütter L, Chappuis V, et al. Early implant placement with simultaneous guided bone regeneration following single-tooth extraction in the esthetic zone: 12-month results of a prospective study with 20 consecutive patients. J Periodontol 2009;80:152-62.

4. Gapski R, Parks CA, Wang HL. Acellular dermal matrix for mucogingival surgery: a meta-analysis.J Periodontol 2005;76:1814-22.

5. Scarano A, Barros RR, Iezzi G, Piattelli A, Novaes AB Jr. Acellular dermal matrix graft for gingival augmentation: a preliminary clinical, histologic, and ultrastructural evaluation. J Periodontol 2009;80:253-9.

6. Shepherd N, Greenwell H, Hill M, Vidal R, Scheetz JP. Root coverage using acellular dermal matrix and comparing a coronally positioned tunnel with and without platelet-rich plasma: a pilot study in humans. J Periodontol 2009;80:397-404.
7. Fang A, Hu SS, Endres N, Bradford DS. Risk factors for infection after spinal surgery. Spine. 2005 Jun 15;30 (12):1460-5.

8. Kainer MA, Linden JV,Whaley DN, Holmes HT, Jarvis WR, Jernigan DB, et al. Clostridium infections associated with musculoskeletal-tissue allografts. N Engl J Med 2004; 350:2564-71.

9. Badylak SF, Freytes DO, Gilbert TW. Extracellular matrix as a biological scaffold material: Structure and function. Acta Biomater 2009;5:1-13.

10. Rosso F, Giordano A, Barbarisi M, Barbarisi A. From cellECM interactions to tissue engineering. J Cell Physiol 2004;199:174-80.

11. Badylak SF. The extracellular matrix as a biologic scaffold material. Biomaterials 2007;28:3587-93.

12. Woods T, Gratzer PF. Effectiveness of three extraction techniques in the development of a decellularized boneanterior cruciate ligament-bone graft. Biomaterials 2005;26:7339-49.

13. Lovekamp JJ, Simionescu DT, Mercuri JJ, Zubiate B, Sacks MS, Vyavahare NR. Stability and function of glycosaminoglycans in porcine bioprosthetic heart valves. Biomaterials 2006;27:1507-18.

14. Freytes DO, Tullius RS, Valentin JE, Stewart-Akers AM, Badylak SF. Hydrated versus lyophilized forms of porcine extracellular matrix derived from the urinary bladder. J Biomed Mater Res A 2008;87:862-72.

15. Freytes DO, Tullius RS, Badylak SF. Effect of storage upon material properties of lyophilized porcine extracellular matrix derived from the urinary bladder. J Biomed Mater Res B Appl Biomater 2006;78:327-33.

16. Gilbert TW, Gilbert S, Madden M, Reynolds SD, Badylak SF. Morphologic assessment of extracellular matrix scaffolds for patch tracheoplasty in a canine model. Ann Thorac Surg 2008;86:967-74.

17. Chiu CK, Lau PY, Chan SW, Fong CM, Sun LK. Microbial contamination of femoral head allografts. Hong Kong Med J 2004;10:401-5.

18. Freytes DO, Stoner RM, Badylak SF. Uniaxial and biaxial properties of terminally sterilized porcine urinary bladder matrix scaffolds. J Biomed Mater Res B Appl Biomater 2008;84:408-14. 
19. Gouk SS, Lim TM, Teoh SH, Sun WQ. Alterations of human acellular tissue matrix by gamma irradiation: histology, biomechanical property, stability, in vitro cell repopulation, and remodeling. J Biomed Mater Res B Appl Biomater 2008;84:205-17.

20. Balsly CR, Cotter AT, Williams LA, Gaskins BD, Moore MA, Wolfinbarger L Jr. Effect of low dose and moderate dose gamma irradiation on the mechanical properties of bone and soft tissue allografts. Cell Tissue Bank 2008;9:289-98.

21. Jackson DW, Windler GE, Simon TM. Intraarticular reaction associated with the use of freeze-dried, ethylene oxide-sterilized bone-patella tendon-bone allografts in the reconstruction of the anterior cruciate ligament. Am J Sports Med 1990;18:1-10.

22. Delmonico FL. Cadaver donor screening for infectious agents in solid organ transplantation. Clin Infect Dis 2000;31:781-6.

23. Simonds RJ, Holmberg SD, Hurwitz RL, Coleman TR, Bottenfield S, Conley LJ, et al. Transmission of human immunodeficiency virus type 1 from a seronegative organ and tissue donor. N Engl J Med 1992 326:72632.

24. Crawford MJ, Swenson CL, Arnoczky SP, O'Shea J, Ross $\mathrm{H}$. Lyophilization does not inactivate infectious retrovirus in systemically infected bone and tendon allografts. Am J Sports Med 2004;32:580-6.
25. Zou S, Dodd RY, Stramer SL, Strong DM. Probability of viremia with HBV, HCV, HIV, and HTLV among tissue donors in the United States. N Engl J Med 2004;351:751-9.

26. Kleinman S. Residual risk of transfusion transmitted viral infections among seronegative donors: application of the incidence/window period model. Dev Biol Stand 2000; 102:61-5.

27. Hathaway JK, Choe JM. Intact genetic material is present in commercially processed cadaver allografts used for pubovaginal slings. J Urol 2002;168:1040-3.

28. Vaishnav S, Thomas Vangsness C Jr, Dellamaggiora R. New techniques in allograft tissue processing. Clin Sports Med 2009;28:127-41.

29. Nakamura, Y., Aso, E. and Yanagawa, H. Relative risk of Creutzfeldt-Jakob disease with cadaveric dura transplantation in Japan. Neurology 1999;53:218-20.

30. Choe JM, Bell T. Genetic material is present in cadaveric dermis and cadaveric fascia lata. J Urol 2001;166: 122-4.

\section{CORRESPONDENCIA}

Carlos Martín Ardila Medina

Carrera 47 No. 20 sur 46

Envigado Antioquía Colombia

57(4) 3348122

martinardila@gmail.com 